\title{
Mechanistic movement models identify continuously updated autumn migration cues in Arctic caribou
}

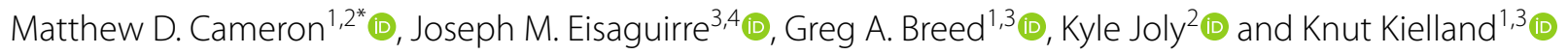

\begin{abstract}
Background: Migrations in temperate systems typically have two migratory phases, spring and autumn, and many migratory ungulates track the pulse of spring vegetation growth during a synchronized spring migration. In contrast, autumn migrations are generally less synchronous and the cues driving them remain understudied. Our goal was to identify the cues that migrants use in deciding when to initiate migration and how this is updated while en route.

Methods: We analyzed autumn migrations of Arctic barren-ground caribou (Rangifer tarandus) as a series of persistent and directional movements and assessed the influence of a suite of environmental factors. We fitted a dynamicparameter movement model at the individual-level and estimated annual population-level parameters for weather covariates on 389 individual-seasons across 9 years.
\end{abstract}

Results: Our results revealed strong, consistent effects of decreasing temperature and increasing snow depth on migratory movements, indicating that caribou continuously update their migratory decision based on dynamic environmental conditions. This suggests that individuals pace migration along gradients of these environmental variables. Whereas temperature and snow appeared to be the most consistent cues for migration, we also found interannual variability in the effect of wind, NDVI, and barometric pressure. The dispersed distribution of individuals in autumn resulted in diverse environmental conditions experienced by individual caribou and thus pronounced variability in migratory patterns.

Conclusions: By analyzing autumn migration as a continuous process across the entire migration period, we found that caribou migration was largely related to temperature and snow conditions experienced throughout the journey. This mechanism of pacing autumn migration based on indicators of the approaching winter is analogous to the more widely researched mechanism of spring migration, when many migrants pace migration with a resource wave. Such a similarity in mechanisms highlights the different environmental stimuli to which migrants have adapted their movements throughout their annual cycle. These insights have implications for how long-distance migratory patterns may change as the Arctic climate continues to warm.

Keywords: Arctic, Bayesian, Caribou, Correlated random walk, Migration cues, Migratory pacing, Movement ecology, Rangifer tarandus, Recursive Bayesian computation, Stopover

\footnotetext{
*Correspondence: matthew_cameron@nps.gov

${ }^{2}$ Gates of the Arctic National Park and Preserve, Arctic Inventory and Monitoring Network, National Park Service, 4175 Geist Road, Fairbanks, AK 99709, USA

Full list of author information is available at the end of the article
}

\begin{abstract}
"A heavy fall of snow appears to be the signal for the start [of autumn migration] if, however, it is followed by a prolonged spell of good weather, the animals either remain scattered about the flat country near Sandy Lake, or they continue slowly and in a very irregular way towards their winter quarters. With the advent of cold or snows the movement invariably becomes more or less general, and is extremely precipitate when the cold is intense or the snowfall unusually heavy."
\end{abstract}

— A. Radclyffe Dugmore, 1913

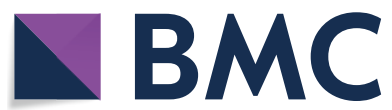

(c) The Author(s) 2021. Open Access This article is licensed under a Creative Commons Attribution 4.0 International License, which permits use, sharing, adaptation, distribution and reproduction in any medium or format, as long as you give appropriate credit to the original author(s) and the source, provide a link to the Creative Commons licence, and indicate if changes were made. The images or other third party material in this article are included in the article's Creative Commons licence, unless indicated otherwise in a credit line to the material. If material is not included in the article's Creative Commons licence and your intended use is not permitted by statutory regulation or exceeds the permitted use, you will need to obtain permission directly from the copyright holder. To view a copy of this licence, visit http://creativecommons.org/licenses/by/4.0/. The Creative Commons Public Domain Dedication waiver (http://creativeco mmons.org/publicdomain/zero/1.0/) applies to the data made available in this article, unless otherwise stated in a credit line to the data. 


\section{Background}

Movement is a fundamental adaptation by animals and migration is a prime example thereof to improve fitness in environments characterized by seasonally predictable spatiotemporal fluctuations in conditions [1-3]. The spatial scale of migration can vary drastically among or even within taxa. Regardless of distance, however, a complete migration trajectory is composed of a series of persistent and directional movements that emerge from a complex suite of physiological and behavioral adaptations $[4,5]$. An integral component for understanding how migratory patterns arise is to identify the cues that migrants use in deciding when to initiate migration and how to move while en route.

For many species, spring migrations are tightly linked to seasonal resource pulses [6-10]. Under the Green Wave Hypothesis, migrants track fronts of emergent, high-quality vegetation to increase nutrient intake as spring progresses along the migratory route [11, 12]. Implicit to this paradigm of spring migration is that herbivores track these emergent vegetative fronts based on the perception of proximate resource quality, permitting migrants to move with resource gradients along the migration route. This is applicable to both temperate migrants in spring and tropical migrants at the beginning of the wet season [13-15]. It does not, however, explain fall migrations in temperate migrants, some Arctic migrants in spring, nor the transition to the dry season for tropical migrants [e.g., 16]. Learning can influence migration and some migrants use their memory more than perception of proximal cues to navigate to distant destinations [17-20]. Regardless of the relative influence of reactive (perception-based) and proactive (learned) mechanisms in driving migration behavior, birthing generally coincides with peak resource quality $[5,21]$, and this likely constrains variability and enhances synchronization of spring migration timing and pace [16, 22, 23].

In contrast to spring migration, autumn migration has been less studied and lacks a common, driving life history event (i.e. birthing) across taxa. Unlike the distinct pulse of vegetation green-up of spring, senescence of vegetation in autumn is prolonged and marked by a gradual decline of forage quality [24]. Perhaps owing to the greater observed variability in autumn phenology patterns during this time, factors influencing autumn migration have received but a fraction of the attention in research on spring migration [25] and autumn migration research still lacks a consistent theoretical framework across taxa.

For temperate ungulate species, vegetative productivity, snow, and temperature influence autumn migration to varying degrees. For example, autumn migrations in roe deer (Capreolus capreolus) and red deer (Cervus elaphus) populations across Europe were influenced by decreased vegetation productivity but not snow events [26]. For red deer in Norway, most individuals left the summer range before the first snowfall, but snow appeared to trigger autumn migration for those that remained [27]. Moreover, migration initiation was associated with decreasing temperatures for females [27] but not with vegetation senescence for either sex [22]. Snow interacts with decreasing temperature in white-tailed deer (Odocoileus virginianus) autumn migrations, such that the first snow to occur in colder temperatures greatly increased the likelihood of migration [28]. Snow and temperature have similar effects on the timing of autumn migration for mule deer $[23,29,30]$. These studies were all conducted for short-distance migrants and it is unclear if these relationships hold for long-distance migrants.

Populations of barren-ground caribou exhibit the longest terrestrial, non-volant migrations on the planet, for which round-trip distances between seasonal ranges can reach 1,350 km [31]. Despite a long history of interest in the drivers of autumn migration in caribou, contemporary research on the topic is surprisingly sparse. In 1913, the early naturalist Arthur Dugmore [32] speculated that the winter's first heavy snowfall and cold temperatures initiated autumn migration for Newfoundland caribou based on local observations. Early fieldwork in Canada drew a connection between the first snowfall and autumn migration [33] and later work in Newfoundland suggested that the first snowfall of 5-10 cm initiated autumn migrations [34]. Anecdotally, autumn migration for the Porcupine Herd in Alaska and far western Canada was once observed to begin following an early season (August) snowstorm [35]. Many of these early field observations also note that autumn migrations slow down or pause altogether if the weather turns mild after such snow events, but resumed when temperatures decreased or snow began to accumulate again [32, 34, 35]. More recently, temporal variation in autumn migration for the George River and Leaf River Herds in northern Canada was linked to conditions en route, with earlier arrival at the winter range associated with deeper snow at the destination [36]. A promising avenue of migration research is to precisely determine how long-distance terrestrial migrants, such as caribou, respond to experienced environmental conditions throughout migration, given inherent annual environmental variability and the dispersed nature of caribou groups in autumn [33].

Previous studies have typically treated autumn migration, and the initiation of it, as a single discrete event, and applied analyses designed to relate environmental covariates to the timing of the start and end of migrations [e.g., 23, 27, 37, 38]. This approach explicitly assumes that 
once initiated, migration continues to its completion. Yet, many long-distance avian migrants [21], as well as migratory ungulates such as mule deer [38], red deer [22], and elk (Cervus canadensis) [39], use stopovers (pauses along the migration route) to replenish reserves, sometimes for many weeks. A promising new concept that incorporates variability in movement along a complete migration trajectory is "migratory pacing," in which an individual continuously adjusts its behavior based on environmental conditions experienced en route [40]. Migratory pacing incorporates stopovers as an example of a distinct change in migration behavior in response to resources, while also incorporating more subtle changes in movement such as different movement rates. Green wave surfing in spring is an example of this behavior in ungulates, in which migrants pace migration to match the wave of spring resource quality $[6,10]$. In contrast, how this concept applies to autumn migration in ungulates remains largely unexplored despite a long history of field observations and anecdotes suggesting a similar pacing-type pattern in many taxa. Recent developments in statistical movement models permit characterizing behavioral indices from GPS location data [41] and enables relating these behavioral states to experienced environmental conditions [ 40 , 42].

We propose that a complete seasonal migration consists of a series of persistent, directional movements (hereafter simply "migratory movements"), that may or may not be interspersed with bouts of non-persistent movement (akin to stopovers) occurring at the individual level $[1,5]$. We test for effects of continuously varying environmental characteristics on autumn migratory movements evaluated as dynamic parameters of a correlated random walk movement model. We examine these metrics in the Western Arctic Herd, a population of migratory, barren-ground caribou in northwest Alaska. We combine recently developed methods to test for effects at the individual level and scale these insights up for population-level inference [40,43]. We hypothesize that (1) autumn migratory movements for caribou are a function of contemporaneous, experienced environmental conditions, (2) migration is paced based on a continuous decision-making process, such that if conditions change, movements are accelerated, adjusted, or paused, and (3) these responses are highly consistent throughout the population and across the study period despite the widely disaggregated nature of caribou in autumn. As we show, environmental conditions that are strongly affected by climate change alter migratory behavior, and we discuss our findings in relation to the potential for a continued change to alter long-distance terrestrial migrations in the Arctic.

\section{Material and methods}

\section{Study population}

We analyzed data from 175 individual collared caribou from the Western Arctic Herd in northwest Alaska, which annually range from approximately $65^{\circ}-71^{\circ} \mathrm{N}$ and $166^{\circ}-150^{\circ} \mathrm{W}$. In autumn, the herd generally migrates from the arctic tundra of Alaska's North Slope, through the rugged Brooks Range with peaks over $2000 \mathrm{~m}$, to lichen-rich uplands and boreal forests south of the mountain range where they spend the winter. Wintering areas vary by year and the herd is typically broadly dispersed at this time [44, 45]. Autumn migration timing varies by year as well, with a trend toward later migration in recent years and proportions of the population not fully migrating south [44, 46]. From 2009 to 2018, GPS collars (Telonics, Mesa, AZ) were deployed on adult females using procedures approved by the State of Alaska Institutional Animal Care and Use Committee (permits 2012031R and 0040-2017-40). Deployments occurred during autumn migration as caribou crossed the Kobuk River in Kobuk Valley National Park. Methods for collar deployment are described elsewhere $[47,48]$. Most collars were set to record locations every $8 \mathrm{~h}$, but some more recently deployed collars recorded locations every 2 or $4 \mathrm{~h}$. For our analysis, the data were subsampled to 8-h location intervals for consistency across all individuals and years. During the study period, the herd size decreased from 355,000 animals in 2009 [46] to 244,000 in 2019 [49].

We analyzed GPS data between August 15 and December 31 for 2010-2018, resulting in nine autumn migration periods. We used 389 individual-season datasets across these 9 years, ranging from 28 in 2010 to 66 in 2016 (Additional File 1: Table S1). Movement rates associated with insect avoidance in mid-summer are the greatest of the year [46, 50]; consequently, we used August 15th as the beginning date for the analysis period based on preliminary investigations of the data which suggested that insect harassment season could extend to mid-August. Winter is characterized by the slowest and most localized movements of the year, and migration is complete by the end of the year $[46,50]$, so we ended the analysis period at the end of December. We only used data for which the collar was active for the entire period, and thus excluded individualseasons where the individual died, was collared during the migratory period, or for which the individual had less than half of the expected GPS locations due to missing collar data (often due to poor satellite network connectivity).

\section{Movement model}

To characterize the behavior of each caribou along its GPS movement track and understand how it was 
related to contemporaneous environmental factors the individual experienced, we fit a continuous-time movement model with a dynamic behavioral parameter similar to that of Eisaguirre et al. [40]. The movement process for the $j$ th individual is given by:

$$
\mathrm{x}_{j, i} \mid \mathrm{x}_{j, i-1}, \mathrm{x}_{j, i-2} \sim \mathcal{N}\left(\mathrm{x}_{j, i-1}+\gamma_{j, i} \frac{\Delta t_{j, i}}{\Delta t_{j, i-1}}\left(\mathrm{x}_{j, i-1}-\mathrm{x}_{j, i-2}\right), \quad \Delta t_{j, i} \sigma_{x, j}^{2} \mathbf{I}\right),
$$

where $\mathbf{x}_{\mathrm{j}, \mathrm{i}}$ is a cartesian coordinate vector of the individual's location at time $t_{j, i}$ and $\mathbf{I}$ is the identity matrix. The model estimates a continuous, time-varying latent variable $\gamma_{j, i} \in[0,1]$. Higher values of $\gamma_{j, i}$ indicate persistent, directional movements and reduced values indicate tortuous, encamped movements [40, 42, 51, 52]. We can therefore interpret higher estimated values of $\gamma_{j, i}$ as an indicator of the degree of migratory behavior expressed along the trajectory. Within the model, $\gamma_{j, i}$ is specified as a linear combination of environmental covariates associated with each location:

$$
\operatorname{logit}\left(\gamma_{j, i}\right) \sim \mathcal{N}\left(\mathbf{Z}_{j, i}^{T} \boldsymbol{\beta}_{j}, \Delta t_{j, i}^{2} \sigma_{v, j}^{2}\right),
$$

representing the effect of the environment on the animal's movement pattern. Here, $\mathbf{Z}_{j, i}$ is a vector that contains the environmental covariates associated with each $\mathbf{x}_{j, i}$, and $\boldsymbol{\beta}_{j}$ is a vector that weights the effects of those covariates on $\gamma_{j, i}$. Full model statement and details are provided in Additional File 2.

We estimated individual model parameters in a Bayesian framework with Hamiltonian Monte Carlo (HMC) using Stan version 2.19.1 [53], program R version 3.6.2 [54], and the package "RStan" version 2.19.3 [55]. The model was fit to each individual season with 3 chains of 100,000 HMC iterations, including 50,000 for burn-in, and thinned by 10 (see Additional File 3 for implementation). Since the initial stage of our analysis was based at the individual level, we scaled our inference up to the annual population level with recursive Bayesian computation using a second stage Markov chain Monte Carlo (MCMC) algorithm [43, 56-58]. We modeled the population-level coefficient $\beta_{\mathrm{p}, \mathrm{k}}$ for the kth covariate as:

$$
\beta_{j, k} \sim \mathcal{N}\left(\beta_{p, k}, \sigma_{\beta, k}^{2}\right) .
$$

We assigned an informative prior centered on zero to each $\beta_{\mathrm{p}, \mathrm{k}}$ to ensure that any apparent effects of environmental covariates detected were relatively strong (see full model statement in Additional File 2). To ensure that our results were not heavily weighted by overrepresenting winter movements in the dataset (that is, movements that were made after migrations had ended), we repeated the analysis and fit models to a truncated movement time-series (August 15 to November 15) and compared these to the original results.

\section{Environmental data}

We attributed environmental variables to the caribou location data using the track annotation service EnvDATA [59] on Movebank (www.movebank.org). For each location, we obtained time-specific point estimates for air temperature $\left({ }^{\circ} \mathrm{C}\right)$, snow accumulation (meters), wind speed $\left(\mathrm{m} \mathrm{sec}^{-1}\right)$, and standardized atmospheric pressure $(\mathrm{Pa})$. These were derived from the North American Regional Reanalysis [60] and are produced at 3-h intervals and 0.3 degree spatial resolution. We also included an index of vegetation greenness, the Normalized Difference Vegetation Index (NDVI), as measured from the MODIS satellite platform for each location with a 250-m resolution [61]. NDVI was derived from 16-day composites and the best image within that time span was used as the value. We set NDVI values to 0 for all locations which had measured snow accumulation, because changes in snow cover drives a large part of the seasonal NDVI patterns in Arctic environments [62]. Bilinear interpolation was used for all attributes in Env-DATA and weather reanalysis data have been found to have good agreement with weather station data collected in the area of the herd [63, 64]. Correlations between environmental variables were all less than 0.7 and all variables were standardized to mean zero and unit variance prior to fitting the model.

To test our hypothesis that migratory behavior is a function of experienced environmental covariates, we fit one model that included the main effects for each environmental covariate. We included an interaction between temperature and snow depth to test for potential additional effects of snow at a given temperature [28]. The expected value of movement persistence was thus modeled as:

$$
\begin{aligned}
E\left(\operatorname{logit}\left(\gamma_{j, i}\right)\right)= & \boldsymbol{Z}_{j, i}^{T} \boldsymbol{\beta}_{j}=\beta_{0}+\beta_{1} \cdot \operatorname{Temp}\left(x_{j, i}\right)+\beta_{2} \cdot \operatorname{Snow}\left(x_{j, i}\right) \\
& +\beta_{3} \cdot \operatorname{Temp}\left(x_{j, i}\right) \cdot \operatorname{Snow}\left(x_{j, i}\right)+\beta_{4} \cdot \operatorname{Wind}\left(x_{j, i}\right) \\
& +\beta_{5} \cdot \operatorname{NDVI}\left(x_{j, i}\right)+\beta_{6} \cdot \operatorname{Pressure}\left(x_{j, i}\right) .
\end{aligned}
$$

We interpreted multiple years of $90 \%$ credible intervals that did not overlap zero for each year of the population-level model to indicate effects of the environmental covariate $[65,66]$. To visualize our results at the 
landscape scale, we downloaded environmental rasters of these given covariates at three characteristic periods (early-, middle-, and late-autumn) in 2010. We then mapped expected movement patterns over the landscape using the equation $\widehat{\gamma}_{\mathrm{i}}=\operatorname{logit}{ }^{-1}\left(\boldsymbol{Z}_{i}^{\boldsymbol{T}} \widehat{\boldsymbol{\beta}}_{p}\right)$, where $\hat{\boldsymbol{\beta}}_{p}$ represents the posterior mean for the population-level coefficients and $Z_{i}^{T}$ the vector of observed environmental conditions in each pixel at a representative date and time. Stan and R code used to implement our approach is provided in Additional File 4.

\section{Results}

Across all 9 years, the combination of snow and temperature had the strongest influence on autumn migratory movements, with estimated coefficients of the interaction term and $90 \%$ credible intervals $(\mathrm{CI})$ that were consistently above zero (Fig. 1). Chain mixing and potential scale reduction statistics $(\widehat{R})$ less than 1.01 for all 389 individual season models indicated convergence to the posterior distribution [53].

Interpretation of the main effects of temperature and snow on migratory movement was nuanced due to the consistently significant interaction term (Fig. 1, Additional file 1: Table S2) and was best interpreted through comparing the effect to migratory movement across a range of both temperature and snow values (Fig. 2). When snow was absent, decreasing temperatures alone resulted in increased migratory movement for all but one year, suggested by higher $\gamma_{j, i}$ at low temperatures (Fig. 2). Accumulating snow depth modulated this relationship between temperature and migratory movement, such that snow accumulation at relatively warmer temperatures in autumn resulted in higher $\gamma_{j, i}$. This was pronounced for the first snow event and early accumulation of snow depth, which were consistently associated with elevated $\gamma_{j, i}$, such that individuals typically exhibited more persistent movements within 10 days of early season snow events (Fig. 3; Additional File 1: Figure S1). Notably, migratory movements were clearly altered as environmental conditions moderated in the days following such events, and animals often exhibited more localized, slower movements (decreased $\gamma_{j, i}$ ) after reaching snow-free areas farther south (e.g., Fig. 3; Additional File 1: Figure S2). Snow appeared to become a hindrance to movement as it accumulated, such that deep snow (e.g., more than $40 \mathrm{~cm}$ ) and cold temperatures (such as -20 to $-30{ }^{\circ} \mathrm{C}$ ) were associated with the most encamped movement behaviors (Figs. 2, 3). For 8 of 9 years, the relationship between temperature and $\gamma_{j, i}$ inverted at an average depth of $12 \mathrm{~cm}$ (range 2 [2010]-21 cm [2017]).

Wind, NDVI, and air pressure had less pronounced and more variable effects on migratory movements. Windy conditions were generally associated with increased migratory movements, as the estimated coefficient was positive for 7 out of 9 years (2010 and 2012-2017). However, evidence was weak as of those, only two had $90 \%$ CIs that did not include zero (Fig. 1; Additional File 1: Figure S3). Increased migratory

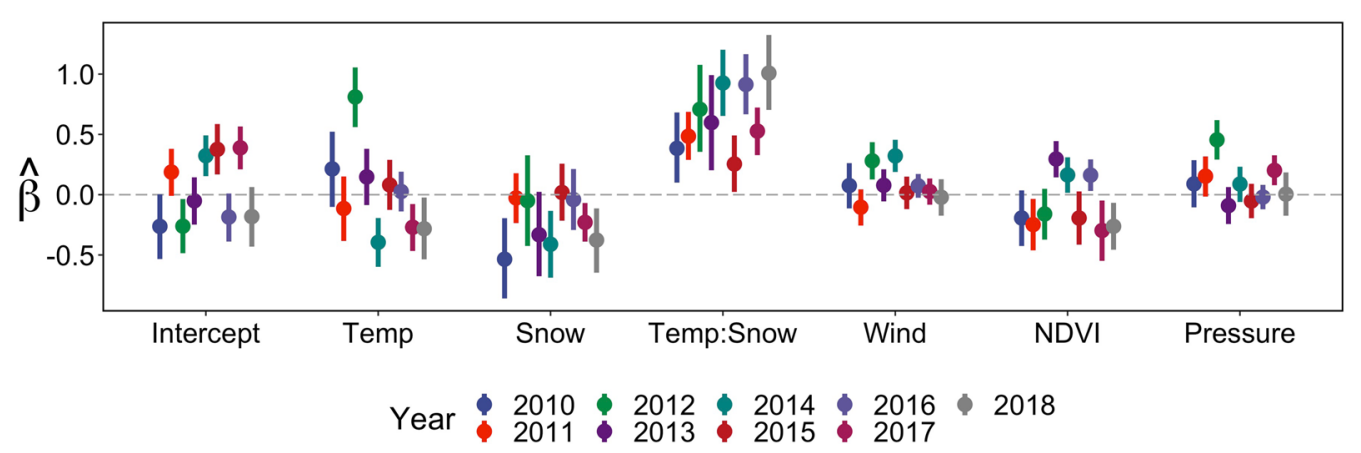

Fig. 1 Annual estimated population-level coefficients (points) and $90 \%$ credible intervals (bars) for the effect of environmental variables on migratory movements $\left(\widehat{\gamma}_{i}\right)$ from the dynamic-parameter correlated random walk model. Environmental variables were standardized and the model was fitted to individual tracks of caribou data from the Western Arctic Herd, Alaska, 2010-2018

(See figure on next page.)

Fig. 2 The effect of temperature at three different snow depth levels for each year from the population-level fit of the dynamic-parameter correlated random walk movement model fitted to caribou location data of the Western Arctic Herd, Alaska, 2010-2018. For each year, the predicted effect of temperature $\left(x\right.$-axis) on the movement parameter $\left(\widehat{\gamma}_{i} ; y\right.$-axis) is plotted across 3 levels of snow depth (no snow $=0 \mathrm{~cm}$, average snow $=11 \mathrm{~cm}$, and deep snow $=46 \mathrm{~cm})$. Each black curve is given by the equation $\widehat{\gamma}_{i}^{(l)}=\operatorname{logit}{ }^{-1}\left(\boldsymbol{Z}_{i}{ }^{\top} \widehat{\boldsymbol{\beta}}_{p}^{(T)}\right)$ for the lth Markov-Chain Monte Carlo iteration (termed posterior realizations), and the red line indicates the mean. Annual plots are cut off to the observed range of values for each year 


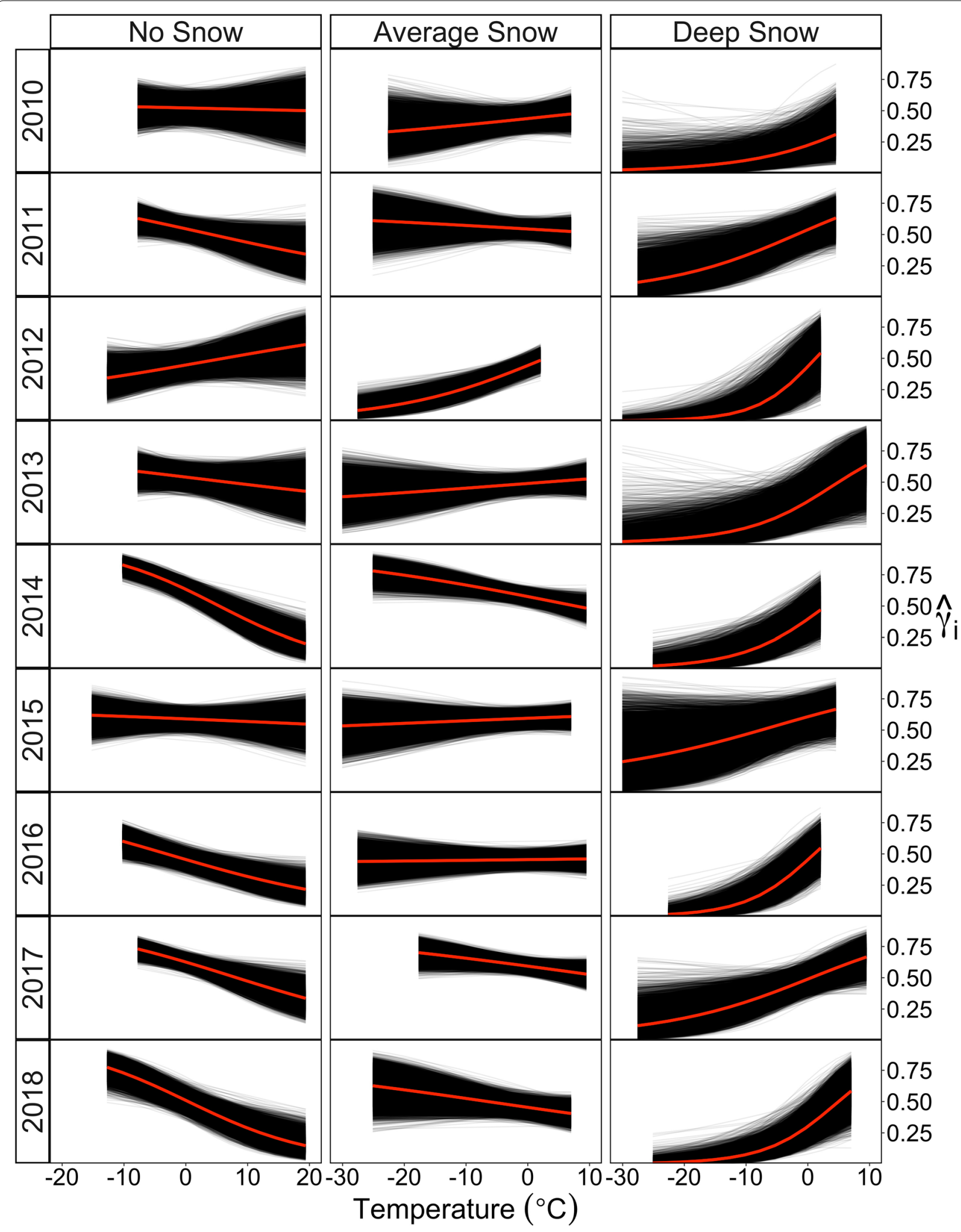

Fig. 2 (See legend on previous page.) 


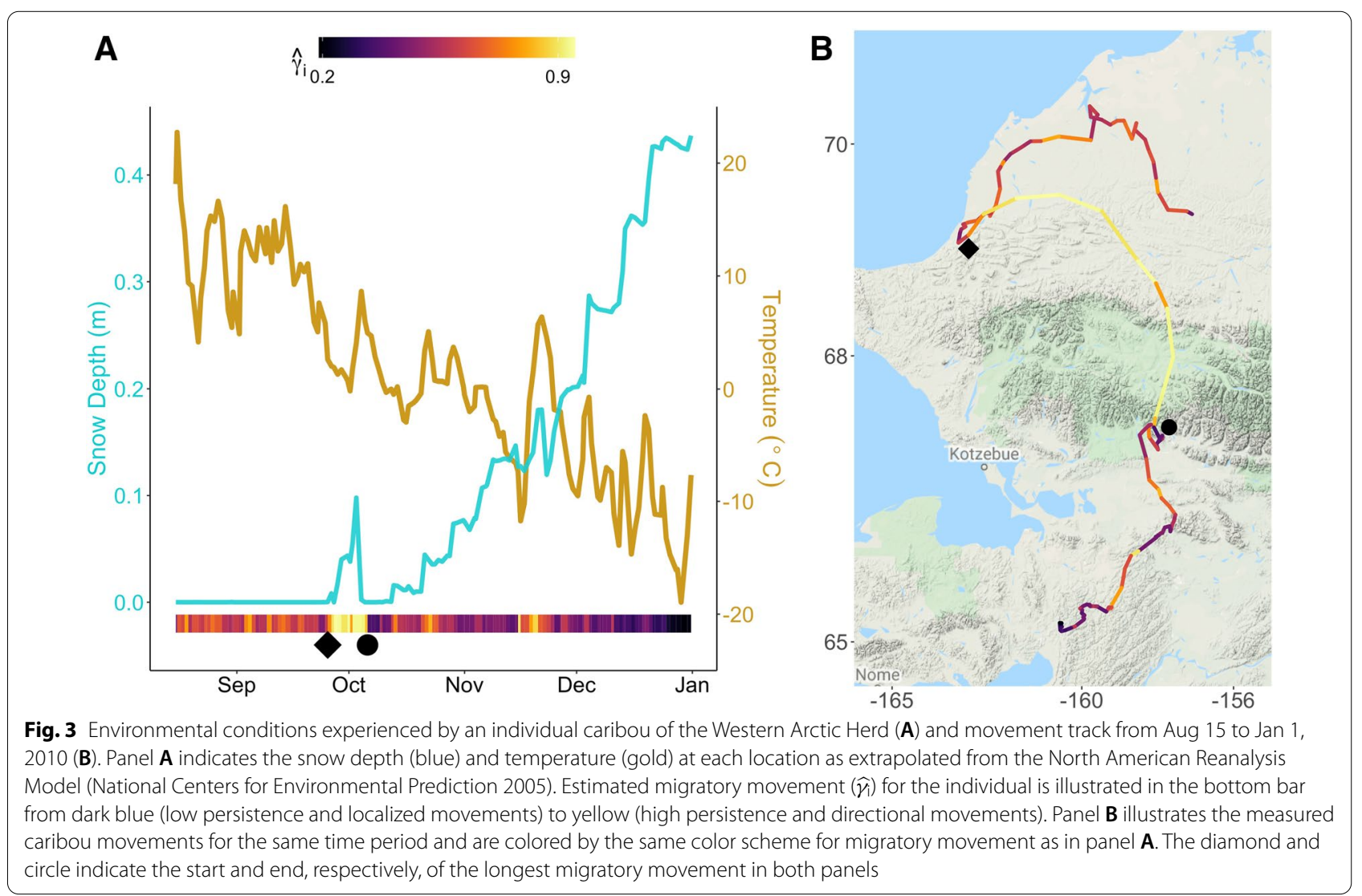

movements were generally associated with decreasing NDVI values, with negative coefficients in 6 years $(90 \%$ CI below zero for 3 years; Fig. 1; Additional File 1: Figure S3). Barometric pressure exhibited a generally positive but again weak effect on migratory movements, with 6 years of positive coefficients and of those, two with a $90 \%$ CI that did not include 0 (Fig. 1; Additional File 1: Figure S3). These patterns among environmental variables and migratory movement were consistent, albeit less pronounced, when models were fitted to the truncated timeseries data that ended Nov. 15 (Additional File 1: Figure S4 \& Figure S5).

When visualizing the spatiotemporally explicit movement patterns predicted from our model, the result was extremely heterogenous expected migratory movements that were highly dependent upon where animals were located on the landscape and were temporally dynamic (Fig. 4). The degree of expected migratory movement at a given time and place was a function of the entire suite of environmental factors experienced by individuals. Once snow depth increased to mid-winter depths, movements were predicted to become encamped and homogeneous in the majority of the range regardless of how far south individuals were (Fig. 4) as individuals ceased migration and entered an overwinter movement regime.

\section{Discussion}

More than a century after Dugmore [32] postulated that accumulating snow, decreasing temperatures, and changes in weather affected autumn migration in caribou, we used modern technology and statistical approaches to quantify the dynamic response by caribou to localized snow and temperature conditions and determined that migration is continuously reassessed throughout the migratory period. Whereas the response to these variables scaled to a consistent population-level pattern (Figs. 1, 2), the dispersion of individuals across a wide geographic area resulted in notable variation in migratory behavior among individuals for any given time due to differences in conditions across the region (Fig. 4). Our findings suggest that autumn migration can be envisioned as the recently introduced concept of migratory pacing, in which individuals continuously adjust migratory behavior based on experienced in situ environmental conditions [40], rather than a single discrete action (i.e. "on/off"). Migratory pacing can include stopover behavior and unifies a set of ideas describing migration patterns across the spring and autumn legs of the complete migratory cycle. While many temperate migrants pace spring migration with the flush of resource quality across the landscape (i.e. 'green wave surfing') [6-10], 


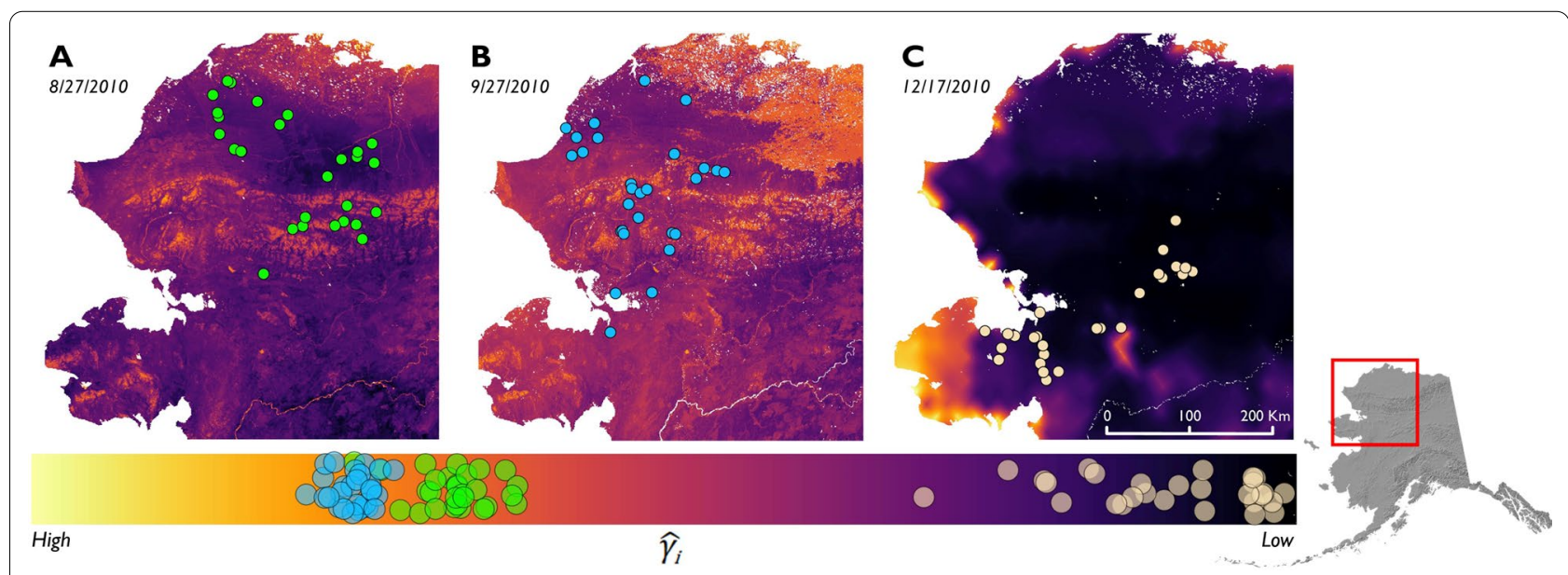

Fig. 4 Predicted migratory movement $\left(\widehat{\gamma_{1}}\right)$ for the range of the Western Arctic Herd given the environmental conditions at three time periods - 8/27 (A), 9/27 (B), and 12/17 (C) - and corresponding population-level model results for individuals in 2010. Dark colors indicate reduced movement persistence (low $\widehat{\gamma_{i}}$ ) and yellow indicate persistent movement (high $\widehat{\gamma_{i}}$ ). Caribou locations are displayed in each panel and colored by day, and the legend bar along the bottom indicates the range of $\widehat{\gamma_{i}}$ and the corresponding values at the observed caribou locations

senescence in autumn is a gradual and protracted decline of vegetation quality that largely ends when snow accumulates [62]. In contrast to spring migration, our results indicate that migrants largely pace autumn migration with respect to indicators of the approaching winter, similar to the 'frost wave' suggested by $\mathrm{Xu}$ and $\mathrm{Si}$ [67]. For caribou, these findings are congruent with early field observations which speculated such a mechanism [32, 34, 35].

Our findings have two important implications for the migratory patterns of populations. The first is that experienced environmental conditions across a population prior to and during migration may exhibit a wide range depending on the spatial distribution of individuals. This is pronounced in caribou, as they are typically dispersed in late summer [33, 68,69], and this is especially true for the Western Arctic Herd [44, 46] (Fig. 4). Secondly, individuals respond to proximate environmental cues in a common manner despite this widespread spatial dispersion of groups. This finding is similar to that for golden eagles (Aquila chrysaetos), which use thermal uplift as a flight subsidy along a variety of autumn (and spring) migration routes [40], as well as elk herds in the Greater Yellowstone Ecosystem, which rely on similar environmental cues for migration timing despite ranges being spatially distinct [70]. Our findings indicate that caribou generally exhibit a common behavioral response to similar proximate weather conditions (snow and temperature) they experience. One notable commonality was elevated movement persistence after the first snowfall event of the season (such as the individual depicted in Fig. 3), which appeared to be representative of the general response we found in our populationlevel results. The dispersed distribution of the herd in late summer results in individuals experiencing different environmental conditions which, in turn, leads to different individual-level migratory decisions. These then scale up to the observed variability and asynchrony in migratory patterns (this study) observed at the population level [44, 46]. More generally, the consistent population-level responses to environmental cues that we detected suggests that variability in environmental conditions experienced across a population's distribution in a given year can explain why autumn migrations can exhibit such wide variability in timing across many taxa [22, 23, 71].

Assessing the influence of the environment along the entire migration trajectory provides a mechanistic link between broad-scale weather patterns and migration, suggesting that changes in the prevailing climate may result in changes to migratory patterns. In the range of the Western Arctic Herd, the climatic trend has been for warmer autumns [72] and has coincided with progressively later autumn migrations over multiple decades $[44,46,73]$. Shifts in autumn migration timing have been linked to environmental trends in other species as well, such as for Chukchi Sea Beluga whales (Delphinapterus leucas) that now migrate later as seasonal sea-ice formation has become delayed [74]. Timing of elk autumn migration in the Greater Yellowstone Ecosystem was found to be highly plastic from 2001 to 2017 and corresponded to changes in snow patterns for many of the herds [70]. Understanding how climate influences migration behavior is important for predicting 
how long-distance migrant populations may or may not respond adaptively to future climate change [75]. This is especially pertinent for rural Arctic subsistence communities, whose cultural identity and way of life date back more than 10,000 years and rely on harvesting caribou during migration [76]. Given the rapid changes currently being observed in the Arctic and even greater ones predicted with climate change [77, 78], our results indicate that caribou migrating long-distances, and perhaps other long-distance migrants, are highly plastic in their decision of when and at what pace to migrate, and that further migration delays could occur if the warming trend continues.

In the later part of the season we analyzed (i.e., late November-December), we found that movement persistence consistently reached its lowest levels as winter conditions set in, which were characterized by deep snow and cold temperatures. This aligns with documented increased costs of winter movements, given that the energy expenditure to move through snow increases exponentially with increased sinking depth (and thus snow depth) [79]. Winter movement rates progressively diminish throughout winter [50] and concurrently, metabolic rates and energy requirements in caribou decrease [80]. These are some of the numerous adaptations by northern species to survive the long winter months [81] and highlight the importance of incorporating snow metrics in studies of animal movements in northern ecosystems $[82,83]$.

Our primary finding that migratory movements are a response to dynamic and localized temperature and snow patterns is consistent with previous research for species exhibiting shorter and less demanding migrations, such as mule deer $[23,29,30]$, white-tailed deer [28, 84], elk [70], and red deer [27]. We also found evidence that vegetation and meteorological conditions can influence migratory movements to lesser degrees. For most years observed, we found a negative relationship between NDVI and migratory movements, indicating caribou travelled more persistently as vegetation senesced and, conversely, were more localized when animals encountered greener vegetation (Fig. 1; Additional File 1: Figure S3). This relationship was not likely to have been driven by snow accumulation (when NDVI values became zero) given the variability in response across years we observed. Our finding that autumn migration timing is related to fall senescence is similar to European populations of roe and red deer, for which migration timing is linked to decreasing plant productivity, as measured by NDVI [26]. Under the migratory pacing concept, individuals may delay not only the start of autumn migrations but also slow down or pause migration en route (stopover) if they encounter improved foraging conditions. This is similar to mule deer, for which stopover sites have higher NDVI values than neighboring migration corridors [38]. Such a tactic could prolong access to good foraging conditions before winter sets in and reduce competition on winter areas by delaying arrival as long as possible. We also found that migratory movements were more persistent on windy, high pressure days in some years, suggesting that migration speed may be modulated by fair weather conditions. Other, less predictable meteorological conditions not considered here, such as rain on snow events, are known to influence caribou movements as well [85]. Autumn migration has been observed during warm weather in the past [47], similar to an anomalous year in our data, and this highlights the need for further research into autumn migration.

\section{Conclusions}

By treating migration as a series of directional and persistent migratory movements and classifying these as a continuous metric, we show that decreasing temperature and increasing snow depth influence when and how caribou migrate in autumn. These quantitative findings align with the early observations of naturalists and field biologists that have accrued over the last century. Because individuals of this caribou herd are dispersed across a large spatial extent in autumn, variability in experienced conditions results in a wide range of observed migration patterns. This mechanism of pacing autumn migration based on indicators of the approaching winter is analogous to the more widely researched mechanism of spring migration, when many migrants pace migration with a resource wave, and highlights the different environmental stimuli migrants have adapted to respond to throughout their annual cycle.

\section{Supplementary Information}

The online version contains supplementary material available at https://doi. org/10.1186/s40462-021-00288-0.

Additional file 1. Additional figures and tables.

Additional file 2. Stan model details.

Additional file 3. Individual-level model implementation.

Additional file 4. Population-level model implementation.

\section{Acknowledgements}

We thank Christa Mulder, Lincoln Parrett, Tom Glass, Abigail Schiffmiller, Julia McMahon, and especially Dr. Jonathan Potts and one anonymous reviewer for their insightful and constructive comments that improved previous versions of this manuscript. We thank Alaska Department of Fish and Game (ADF\&G) biologists Lincoln Parrett and Alex Hansen for their numerous discussions on the banks of the Kobuk River during autumn migration that furthered these ideas, and for their dedicated work to collaboratively monitor the Western Arctic Herd. We thank Regan Sarwas for his steadfast efforts in the organization of this GPS database for over a decade. Funding for this project was provided by the National Park Service (NPS) and the ongoing caribou collaring program is funded by ADF\&G and NPS. 


\section{Authors' contributions}

MDC, KJ, GB, JME, and KK conceived the idea for this manuscript. KJ and MDC coordinated and performed the collection of location data. JME and MDC developed and performed the analysis. MDC wrote the manuscript and all authors critically revised the manuscript. All authors read and approved the final manuscript.

\section{Funding}

Funding for this project was provided by the National Park Service (NPS) and the ongoing caribou collaring program is funded by the Alaska Department of Fish and Game and NPS.

\section{Availability of data and materials}

The GPS data used in this study are owned by National Park Service and Alaska Department of Fish and Game, both of which restrict the availability of location data for a harvestable species. All GPS data are stored in the public repository IRMA and are available from the project leads on reasonable request: https://irma.nps.gov/DataStore/Reference/Profile/2260262.

\section{Declarations}

\section{Ethics approval and consent to participate}

Not applicable.

\section{Consent for publication}

Not applicable.

\section{Competing interests}

The authors declare that they have no competing interests.

\section{Author details}

'Department of Biology and Wildlife, University of Alaska Fairbanks, 2090 Koyukuk Drive, Fairbanks, AK 99775, USA. ${ }^{2}$ Gates of the Arctic National Park and Preserve, Arctic Inventory and Monitoring Network, National Park Service, 4175 Geist Road, Fairbanks, AK 99709, USA. ${ }^{3}$ Institute of Arctic Biology, University of Alaska Fairbanks, 2140 Koyukuk Drive, Fairbanks, AK 99775, USA. ${ }^{4}$ Present Address: U.S. Fish and Wildlife Service, Marine Mammals Management, 1011 E. Tudor Rd., Anchorage, AK 99503, USA.

Received: 1 July 2021 Accepted: 7 October 2021 Published online: 01 November 2021

\section{References}

1. Dingle H, Drake VA. What is migration? Bioscience. 2007:57:113-21.

2. Fryxell JM, Sinclair ARE. Causes and consequences of migration by large herbivores. Trends Ecol Evol. 1988;3:237-41.

3. Martin J, Tolon V, Morellet N, Santin-Janin H, Licoppe A, Fischer C, et al. Common drivers of seasonal movements on the migration-residency behavior continuum in a large herbivore. Sci Rep. 2018;8:7631.

4. Åkesson S, Hedenström A. How migrants get there: migratory performance and orientation. Bioscience. 2007:57:123-33.

5. Dingle H. Migration: the biology of life on the move. New York, New York: Oxford University Press; 1996.

6. Rivrud IM, Heurich M, Krupczynski P, Müller J, Mysterud A. Green wave tracking by large herbivores: an experimental approach. Ecology. 2016;97:3547-53

7. Merkle JA, Monteith KL, Aikens EO, Hayes MM, Hersey KR, Middleton AD, et al. Large herbivores surf waves of green-up in spring. Proc R Soc B Biol Sci. 2016:283:20160456.

8. Aikens EO, Kauffman MJ, Merkle JA, Dwinnell SPH, Fralick GL, Monteith $\mathrm{KL}$. The greenscape shapes surfing of resource waves in a large migratory herbivore. Ecol Lett. 2017:20:741-50.

9. Middleton AD, Merkle JA, Mcwhirter DE, Cook JG, Cook RC, White PJ, et al. Green-wave surfing increases fat gain in a migratory ungulate. Oikos. 2018;1060-8.

10. Aikens EO, Mysterud A, Merkle JA, Cagnacci F, Rivrud IM, Hebblewhite M, et al. Wave-like patterns of plant phenology determine ungulate movement tactics. Curr Biol. 2020;30:3444-9.
11. Bischof R, Loe LE, Meisingset EL, Zimmermann B, Van Moorter B, Mysterud A. A migratory northern ungulate in the pursuit of spring: Jumping or surfing the green wave? Am Nat. 2012;180:407-24.

12. van der Graaf S, Stahl J, Klimkowska A, Bakker JP, Drent RH. Surfing on a green wave-how plant growth drives spring migration in the Barnacle Goose Branta leucopsis. Ardea. 2006;94:567-77.

13. Boone RB, Thirgood SJ, Hopcraft JGC. Serengeti wildebeest migratory patterns modeled from rainfall and new vegetation growth. Ecology. 2006:87:1987-94.

14. Holdo RM, Holt RD, Fryxell JM. Opposing rainfall and plant nutritional gradients best explain the wildebeest migration in the serengeti. Am Nat. 2009:173:431-45.

15. Hopcraft JGC, Morales JM, Beyer HL, Borner M, Mwangomo E, Sinclair $A R E$, et al. Competition, predation, and migration: individual choice patterns of Serengeti migrants captured by hierarchical models. Ecol Monogr. 2014;84:355-72.

16. Gurarie E, Hebblewhite M, Joly K, Kelly AP, Adamczewski J, Davidson SC, et al. Tactical departures and strategic arrivals: divergent effects of climate and weather on caribou spring migrations. Ecosphere. 2019;10:e02971.

17. Bracis C, Mueller T. Memory, not just perception, plays an important role in terrestrial mammalian migration. Proc R Soc B Biol Sci. 2017;284:20170449.

18. Abrahms B, Hazen EL, Aikens EO, Savoca MS, Goldbogen JA, Bograd SJ. Memory and resource tracking drive blue whale migrations. Proc Natl Acad Sci. 2019:116:1-6.

19. Merkle JA, Sawyer H, Monteith KL, Dwinnell SPH, Fralick GL, Kauffman MJ. Spatial memory shapes migration and its benefits: evidence from a large herbivore. Ecol Lett. 2019;22:1797-805

20. Cameron MD, Joly K, Breed GA, Mulder CPH, Kielland K. Pronounced fidelity and selection for average conditions of calving area suggestive of spatial memory in a highly migratory ungulate. Front Ecol Evol. 2020;8:564

21. Newton I. The migration ecology of birds. London: Elsevier; 2008.

22. Debeffe L, Rivrud IM, Meisingset EL, Mysterud A. Sex-specific differences in spring and autumn migration in a northern large herbivore. Sci Rep. 2019;9:6137.

23. Monteith KL, Bleich VC, Stephenson TR, Pierce BM, Conner MM, Klaver RW et al. Timing of seasonal migration in mule deer: effects of climate, plant phenology, and life-history characteristics. Ecosphere. 2011;2:art47.

24. Chapin FS, Van Cleve K, Tieszen LL. Seasonal nutrient dynamics of tundra vegetation at Barrow, Alaska. Arct Alp Res. 1975;7:209-26.

25. Gallinat AS, Primack RB, Wagner DL. Autumn, the neglected season in climate change research. Trends Ecol Evol. 2015:30:169-76.

26. Peters W, Hebblewhite M, Mysterud A, Eacker D, Hewison AJM, Linnel JDC, et al. Large herbivore migration plasticity along environmental gradients in Europe: life-history traits modulate forage effects. Oikos. 2019;128:416-29.

27. Rivrud IM, Bischof R, Meisingset EL, Zimmermann B, Loe LE, Mysterud A. Leave before it's too late: anthropogenic and environmental triggers of autumn migration in a hunted ungulate population. Ecology. 2016;97:1058-68.

28. Nelson ME. Winter range arrival and departure of white-tailed deer in northeastern Minnesota. Can J Zool. 1995;73:1069-76.

29. Rittenhouse CD, Mong TW, Hart T. Weather conditions associated with autumn migration by mule deer in Wyoming. Peer J. 2015;3:e1045.

30. Brinkman TJ, Deperno CS, Jenks JA, Haroldson BS, Osborn RG. Movement of female white-tailed deer: effects of climate and intensive row-crop agriculture. J Wildl Manage. 2005;69:1099-111.

31. Joly K, Gurarie E, Sorum MS, Kaczensky P, Cameron MD, Jakes AF, et al. Longest terrestrial migrations and movements around the world. Sci Rep. 2019:9:15333

32. Dugmore AR. The romance of the Newfoundland caribou: An intimate account of the life of the reindeer of North America. JB Lippincott Company; 1913

33. Kelsall JP. The migratory barren-ground caribou of North America. Ottawa, Canada: Queen's Printer; 1968.

34. Bergerud AT. The role of the environment in the aggregation, movement and disturbance behaviour of caribou. In: Geist V, Walther F, editors. The behavior of ungulates and its relation to management. International Union for Conservation of Nature and Natural Resources, Morges, Switzerland; 1974. p. 552-84 
35. Whitten KR, Mauer FJ, Garner GW, Russell DE. Fall and Winter movements, distribution, and annual mortality patterns of the porcupine Caribou Herd, 1984-1985. ANWR Prog Rep Number FY86-21. 1986

36. Le Corre M, Dussault C, Côté SD. Weather conditions and variation in timing of spring and fall migrations of migratory caribou. J Mammal. 2017;98:260-71.

37. White PJ, Proffitt KM, Mech LD, Evans SB, Cunningham JA, Hamlin KL. Migration of northern Yellowstone elk: implications of spatial structuring. J Mammal. 2010:91:827-37.

38. Sawyer $\mathrm{H}$, Kauffman MJ. Stopover ecology of a migratory ungulate. J Anim Ecol. 2011:80:1078-87.

39. Paton DG, Ciuti S, Quinn M, Boyce MS. Hunting exacerbates the response to human disturbance in large herbivores while migrating through a road network. Ecosphere. 2017;8:e01841.

40. Eisaguirre JM, Auger-Méthé M, Barger CP, Lewis SB, Booms TL, Breed GA. Dynamic-parameter movement models reveal drivers of migratory pace in a soaring bird. Front Ecol Evol. 2019;7:1-14.

41. Hooten MB, Johnson DS, Mcclintock BT, Morales JM. Animal movement: statistical models for telemetry data. CRC Press; 2017.

42. Jonsen ID, McMahon CR, Patterson TA, Auger-Méthé M, Harcourt R, Hindell MA, et al. Movement responses to environment: fast inference of variation among southern elephant seals with a mixed effects model. Ecology. 2019;100:1-8.

43. Hooten MB, Buderman FE, Brost BM, Hanks EM, Ivan JS. Hierarchical animal movement models for population-level inference. Environmetrics. 2016;27:322-33.

44. Joly K, Cameron MD. Caribou vital sign annual report for the Arctic Network Inventory and Monitoring Program: September 2019-August 2020. Natural Resource Report NPS/ARCN/NRR—2020/2210. National Park Service, Fort Collins, CO; 2020.

45. Joly K, Gurarie E, Hansen DA, Cameron MD. Seasonal patterns of spatial fidelity and temporal consistency in the distribution and movements of a migratory ungulate. Ecol Evol. 2021;11:8183-200.

46. Dau JR. Units 21D, 22A, 22B, 22C, 22D, 22E, 23, 24 and 26A. Chapter 14, pages 14-1 through 14-89. In: Harper P, McCarthy LA, editors. Caribou Manag Rep Surv Invent Act 1 July 2012-30 June 2014. Alaska Department of Fish and Game, Species Management Report ADF\&G/DWC/SMR2015-4, Juneau; 2015.

47. Dau JR. Units 21D, 22A, 22B, 23, 24, 26A caribou management report. In: Hicks M V., editor. Caribou Manag Rep Surv Act 1 July 1994-30 June 1996. Alaska Department Fish and Game, Division of Wildlife Conservation, Federal Aid in Wildlife Restoration Study 3.0. Juneau; 1997. p. 158-185.

48. Joly K, Miller SD, Shults BS. Caribou monitoring protocol for the Arctic Network Inventory and Monitoring Program. Natural Resource Report NPS/ARCN/NRR - 2012/564. National Park Service, Fort Collins, Colorado; 2012.

49. Alaska Department of Fish and Game. Western Arctic Caribou Herd Working Group - 2019 Meeting Summary [Internet]. 2019. Available from: https://westernarcticcaribou.net/wp-content/uploads/2020/03/ 2019-WACH-WG-Meeting-Summary-DRAFT-for-WACH-WG-approval-at2020-mtg.pdf

50. Joly K, Couriot O, Cameron MD, Gurarie E. Behavioral, physiological, demographic and ecological impacts of hematophagous and endoparasitic insects on an Arctic ungulate. Toxins. 2020;12:1-9.

51. Breed GA, Costa DP, Jonsen ID, Robinson PW, Mills-Flemming J. Statespace methods for more completely capturing behavioral dynamics from animal tracks. Ecol Modell. 2012;235-236:49-58.

52. Auger-Méthé M, Albertsen CM, Jonsen ID, Derocher AE, Lidgard DC, Studholme KR, et al. Spatiotemporal modelling of marine movement data using Template Model Builder (TMB). Mar Ecol Prog Ser. 2017:565:237-49.

53. Carpenter B, Gelman A, Hoffman MD, Lee D, Goodrich B, Betancourt $M$, et al. Stan: a probabilistic programming language. J Stat Softw. 2017;76:1-32.

54. R Core Team. R: A language and environment for statistical computing [Internet]. Vienna, Austria: R Foundation for Statistical Computing; 2019 Available from: https://www.r-project.org/

55. Stan Development Team. RStan: the R interface to Stan. R package version 2.19.3; 2020

56. Lunn D, Barrett J, Sweeting M, Thompson S. Fully Bayesian hierarchical modelling in two stages, with application to meta-analysis. J R Stat Soc Ser C Appl Stat. 2013:62:551-72.
57. Hooten MB, Hefley TJ. Bringing Bayesian models to life. Boca Raton, Florida: CRC Press; 2019.

58. Hooten MB, Johnson DS, Brost BM. Making recursive bayesian inference accessible. Am Stat. Taylor \& Francis; 2019;1-10.

59. Dodge S, Bohrer G, Weinzierl R, Davidson SC, Kays R, Douglas D, et al. The environmental-data automated track annotation (Env-DATA) system: linking animal tracks with environmental data. Mov Ecol. 2013;1:1-14.

60. National Centers for Environmental Prediction/National Weather Service/ NOAA/U.S. Department of Commerce. 2005, updated monthly. NCEP North American Regional Reanalysis (NARR). Research Data Archive at the National Center for Atmospheric Research, Computational and Information Systems Laboratory. Accessed: 15 January 2020 from http://rda.ucar. edu/datasets/ds608.0/.

61. Didan, K. 2015. MYD13Q1 MODIS/Aqua Vegetation Indices 16-Day L3 Global $250 \mathrm{~m}$ SIN Grid V006. NASA EOSDIS Land Processes DAAC. Accessed 202001-16 from https://doi.org/10.5067/MODIS/MYD13Q1.006.

62. Swanson DK. Start of the green season and normalized difference vegetation index in Alaska's Arctic National Parks. Remote Sens. 2021;13:1-12.

63. Lindsay R, Wensnahan M, Schweiger A, Zhang J. Evaluation of seven different atmospheric reanalysis products in the arctic. J Clim. 2014;27:2588-606.

64. Lader R, Bhatt US, Walsh JE, Rupp TS, Bieniek PA. Two-meter temperature and precipitation from atmospheric reanalysis evaluated for Alaska. J Appl Meteorol Climatol. 2016;55:901-22.

65. Gelman A, Carlin J. Beyond power calculations: Assessing type S (sign) and type M (magnitude) errors. Perspect Psychol Sci. 2014;9:641-51.

66. Kruschke J. Doing Bayesian data analysis: a tutorial with R, JAGS, and Stan. New York: Academic Press; 2015

67. Xu F, Si Y. The frost wave hypothesis: How the environment drives autumn departure of migratory waterfowl. Ecol Indic. 2019;101:1018-25.

68. Person BT, Prichard AK, Carroll GM, Yokel DA, Suydam RS, George JC Distribution and movements of the Teshekpuk Caribou Herd 1990-2005: Prior to oil and gas development. Arctic. 2007;60:238-50.

69. Russell DE, Whitten KR, Farnell R, van de Wetering D. Movements and distribution of the Porcupine Caribou Herd, 1970-1990. Technical Report Series No. 138. British Columbia; 1992.

70. Rickbeil GJM, Merkle JA, Anderson G, Atwood MP, Beckmann JP, Cole EK, et al. Plasticity in elk migration timing is a response to changing environmental conditions. Glob Chang Biol. 2019;25:2368-81.

71. Cagnacci F, Focardi S, Heurich M, Stache A, Hewison AJM, Morellet N, et al. Partial migration in roe deer: migratory and resident tactics are end points of a behavioural gradient determined by ecological factors. Oikos. 2011;120:1790-802

72. Walsh JE, Brettschneider B. Attribution of recent warming in Alaska. Polar Sci. 2019;21:101-9.

73. Dau JR. Units 21D, 22A, 22B, 22C, 22D, 22E, 23, 24 and 26A caribou management report. Pages. In: Harper P, editor. Caribou Manag Rep Surv Invent Act 1 July 2004-30 June 2006. Juneau: Alaska Department of Fish and Game. Project 3.0; 2007. p. 174-231.

74. Hauser DDW, Laidre KL, Stafford KM, Stern HL, Suydam RS, Richard PR Decadal shifts in autumn migration timing by Pacific Arctic beluga whales are related to delayed annual sea ice formation. Glob Chang Biol. 2017:23:2206-17.

75. Shaw AK. Drivers of animal migration and implications in changing environments. Evol Ecol. 2016:30:991-1007.

76. Anderson D. Onion portage: the archaeology of a stratified site from the Kobuk River. Northwest Alaska Anthropol Pap Univ Alaska. 1988;22:1-163.

77. IPCC. Synthesis Report. Contribution of Working Groups I, II and III to the Fifth Assessment Report of the Intergovernmental Panel on Climate Change. Geneva, Switzerland; 2014

78. Hinzman LD, Bettez ND, Bolton WR, Chapin FS, Dyurgerov MB, Fastie CL, et al. Evidence and implications of recent climate change in Northern Alaska and other Arctic regions. Clim Change. 2005;72:251-98.

79. Fancy SG, White RG. Energy expenditures for locomotion by barrenground caribou. Can J Zool. 1987;65:122-8.

80. Boertje RD. An energy model for adult female caribou of the Denali Herd. Alaska J Range Manag. 1985;38:468.

81. White R, Holleman DF, Hubbert ME, Staaland H. Herbivores in cold climates. In: Hacker JB, Ternouth JH, editors. Nutr Herbiv. Orlando: Academic Press; 1987. p. 465-86. 
82. Pruitt WO. Snow as a factor in the winter ecology of the barren-ground caribou (Rangifer arcticus). Arctic. 1959;12:158-79.

83. Boelman N, Liston GE, Gurarie E, Meddens AJH, Mahoney PJ, Kirchner PB, et al. Integrating snow science and wildlife ecology in Arctic-boreal North America. Environ Res Lett. 2019;14:010401.

84. Sabine DL, Morrison SF, Whitlaw HA, Ballard WB, Forbes GJ, Bowman J. Migration behavior of white-tailed deer under varying winter climate regimes in New Brunswick. J Wildl Manage. 2002;66:718-28.
85. Bieniek PA, Bhatt US, Walsh JE, Lader R, Griffith B, Roach JK, et al. Assessment of Alaska rain-on-snow events using dynamical downscaling. J Appl Meteorol Climatol. 2018;57:1847-63.

\section{Publisher's Note}

Springer Nature remains neutral with regard to jurisdictional claims in published maps and institutional affiliations.
Ready to submit your research? Choose BMC and benefit from:

- fast, convenient online submission

- thorough peer review by experienced researchers in your field

- rapid publication on acceptance

- support for research data, including large and complex data types

- gold Open Access which fosters wider collaboration and increased citations

- maximum visibility for your research: over 100M website views per year

At BMC, research is always in progress.

Learn more biomedcentral.com/submissions 